\title{
Two patients with the same type of iatrogenic disease
}

\author{
B. Vandooren, C. Haenebalcke and Y. Bogaerts
}

\section{CASE HISTORIES}

\section{Case 1}

A 67-yr-old female, who was recently diagnosed as having multiple myeloma, presented with dyspnoea on exertion of $\sim 3$ months' duration (fig. 1). The day before presentation, the patient had developed a cough productive of green-brown sputa and increasing dyspnoea. On clinical examination, a tachypnoeic patient with bibasal crepitations on lung auscultation and without fever was observed. Arterial blood analysis showed an arterial oxygen tension $\left(\mathrm{Pa}_{\mathrm{a}_{2}} \mathrm{O}_{2}\right)$ of $8.71 \mathrm{kPa}$ and an arterial carbon dioxide tension $\left(\mathrm{Pa}_{\mathrm{a}}, \mathrm{CO}_{2}\right)$ of $5.32 \mathrm{kPa}$.

\section{Case 2}

A 66-yr-old female, with a history of chronic obstructive pulmonary disease (COPD), presented with dyspnoea on exertion and anorexia, which had been present for 4 months (fig. 2). Four days prior to presentation, the dyspnoea had
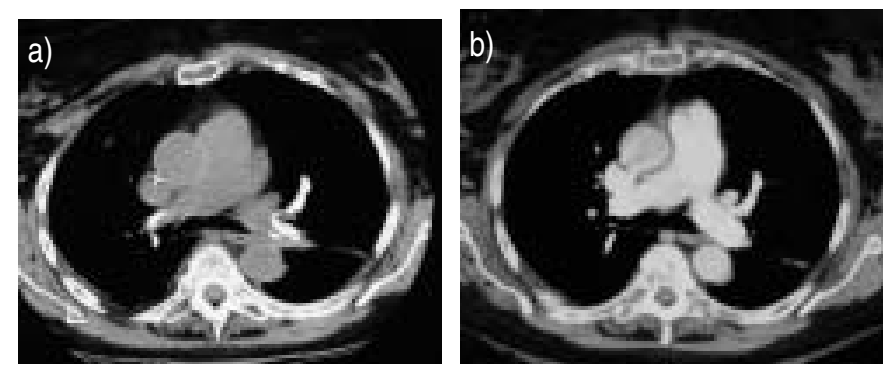

FIGURE 1. Case 1. Thoracic computed tomographic section through the central pulmonary arteries: a) without and b) with contrast medium injection.

increased, and she was coughing up mucoid sputa. On clinical examination, a normopnoeic patient with diffuse wheezing and rhonchi but no fever was observed. Arterial blood analysis showed a $\mathrm{Pa}_{1} \mathrm{O}_{2}$ of $10.79 \mathrm{kPa}$ and a $\mathrm{Pa}_{1} \mathrm{CO}_{2}$ of $4.44 \mathrm{kPa}$. Spirometric results were obstructive (vital capacity: $2.39 \mathrm{~L}$ ( $88 \%$ predicted); forced expiratory volume in one second: 2.27 $\mathrm{L}(72 \%$ pred)) and the transfer factor of the lung for carbon monoxide was reduced (to $4.6 \mathrm{mmoL} \cdot \mathrm{min}^{-1} \cdot \mathrm{kPa}^{-1}$ (62\% pred)).

Both patients had undergone a surgical procedure a few months prior to these findings.

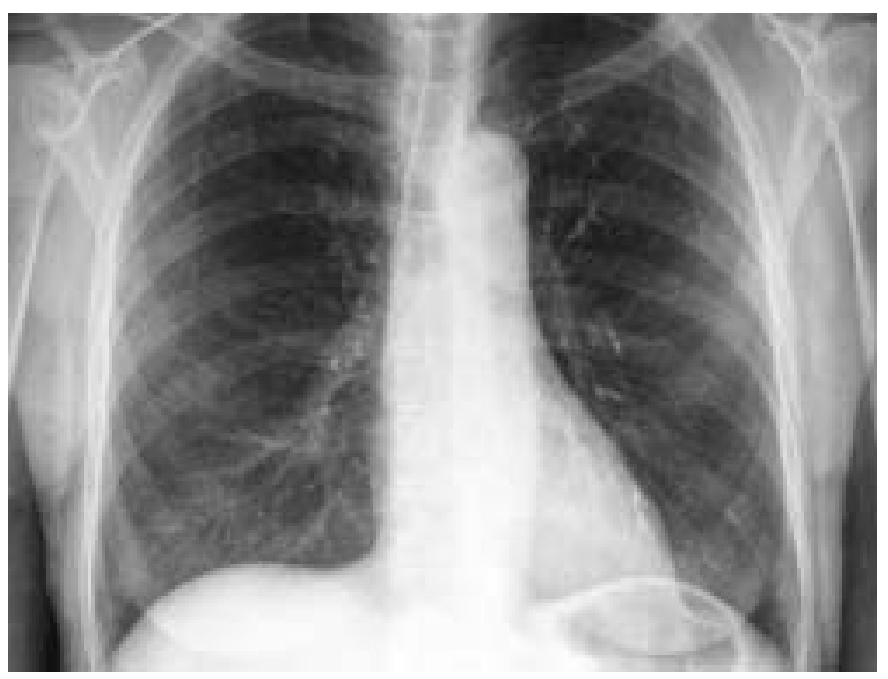

FIGURE 2. Case 2. Plain chest radiograph.

\section{BEFORE TURNING THE PAGE, INTERPRET THE RADIOGRAPHS AND SUGGEST A DIAGNOSIS. WHAT PROCEDURE CAUSED THE DISEASE?}




\section{INTERPRETATION}

The thoracic computed tomography (CT) scans of the first case (fig. 1) show radio-opaque material within the lumen of both central pulmonary arteries. The plain chest radiograph of the second patient (fig. 2) depicts multiple branching densities radiating from the hili, suggesting the presence of radiopaque material in the pulmonary arteries; a subsequent CT scan (not shown) revealed small round opacities in the periphery of the lung.

A few months prior to admission, both patients had undergone a percutaneous vertebroplastic procedure because of persisting back pain after compression fractures of lumbar vertebrae. The post-procedure radiographs of the lumbar spine (figs. 3 and 4) show not only the opacification of the treated vertebrae but also extravertebral leakage of cement into the epidural space and perivertebral veins. Directly after the procedure, the first patient did not experience any respiratory problems. The second patient, however, remembered having had a serious nonproductive cough, which had subsided spontaneously after $\sim 2$ days.

\section{Diagnosis: Embolisation of cement after percutaneous vertebroplasty.}

\section{TREATMENT}

In both patients, treatment with warfarin was initiated. Since the second patient had a concomitant COPD exacerbation, methylprednisolone and bronchodilators were also given.

\section{DISCUSSION}

Percutaneous vertebroplasty is a novel minimally invasive technique for the treatment of vertebral compression fractures. This technique consists of injection, under high pressure, of a mixture of polymethylmethacrylate (PMMA) and a radiopaque substance (barium sulphate or tungsten powder) after local

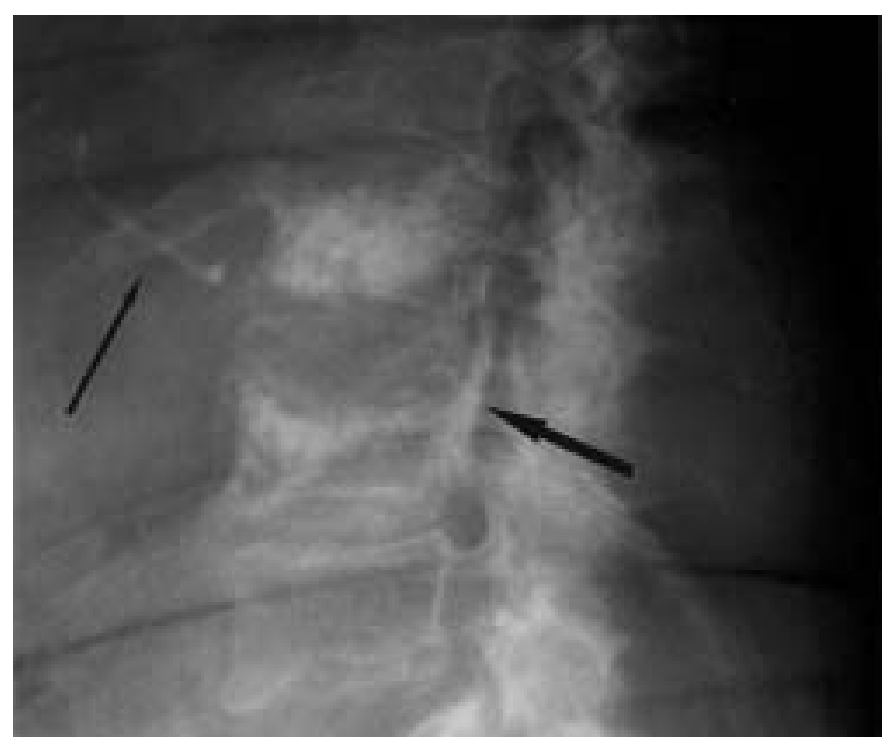

FIGURE 3. Case 1. Lumbar spine radiograph. Radiopaque material in the corpus of the third and fourth lumbar vertebrae, with spilling of cement in the epidural space (thick arrow) and in a perivertebral vein (thin arrow).

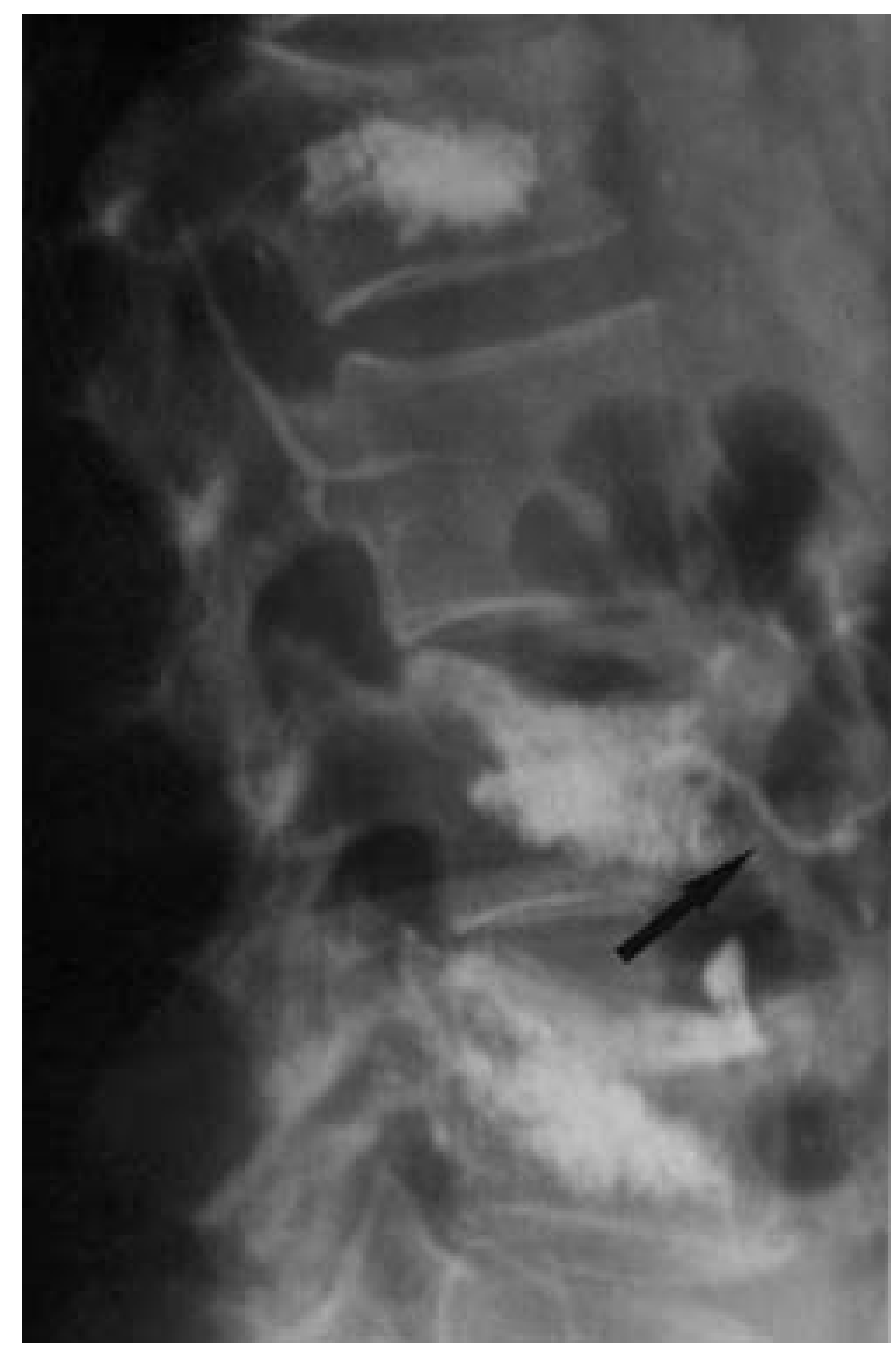

FIGURE 4. Case 2. Lumbar spine radiograph. Radiopaque material in the corpus of the first, third and fourth lumbar vertebrae, with spilling in a perivertebral vein (arrow).

anaesthesia of the skin and subcutis and subsequent placement of a needle in the vertebral corpus. This procedure is performed under fluoroscopic guidance in order to visualise correct placement of the needle and monitor leakage of PMMA (cement) into the perivertebral venous plexus or epidural space. The major indication for this treatment is back pain caused by osteoporotic or malignant (osteolytic metastasis or multiple myeloma) vertebral compression fractures and resistant to conservative medical therapy. For this indication, although no results of prospective sham-operation-controlled trials have been published to date, a beneficial effect on pain is reported [1, 2].

Extravertebral leakage of cement is the most frequent complication of percutaneous vertebroplasty and occurs in up to $65 \%$ of patients [3]. Feared consequences of this spillage are spinal cord or nerve root compression due to accumulation of cement in the epidural space, and embolisation of cement into the pulmonary vasculature following leakage of PMMA into the perivertebral venous plexus. Symptomatic embolisation 
of PMMA into the lung vessels is a rare $(<1 \%)$ complication of this procedure [4], although in none of the studies that evaluated percutanous vertebroplasty were systematic postprocedure chest radiographs performed. Therefore, we believe that there could be serious underestimation of the frequency of this complication. The reported symptomatology ranges from no symptoms [5], through mild dyspnoea, coughing and chest pain [6,7], and to acute perprocedural respiratory distress with right cardiac failure and renal failure [8] or even stroke due to migration of PMMA emboli through a patent foramen ovale [9]. The risk of pulmonary cement embolism, and that of complications altogether, is thought to be greater if the injection of PMMA is performed into a well-vascularised tumour (e.g. Kahler's disease or osteolytic metastasis) rather than into an osteoporotic compression fracture [4]. This was probably the case in the first patient, who was diagnosed as having Kahler's disease 3 months after the procedure.

A number of precautions can be taken to lower the risk of embolisation. PMMA has to be mixed with a radiopaque substance (e.g. barium sulphate or tungsten powder) and the procedure performed under fluoroscopy; if leakage is seen in the perivertebral veins during injection, the needle should be replaced. Before injection, the PMMA needs to have hardened sufficiently and the volume of PMMA injected should be as low as possible [10]. In the second case, the cement was clearly too fluid during the injection, since the migrated PMMA adopted the shape of the smaller pulmonary arteries after arrival in the lung. Whether the surgeon should inject contrast medium into the vertebra, in order to visualise extravertebral leakage, before cement injection remains a matter of debate [11]. A very recently introduced procedure for the treatment of vertebral compression fractures, kyphoplasty, is claimed to exhibit a lower risk of extravertebral leakage of cement and thus also of cement embolisms. This technique is comparable to percutaneous vertebroplasty, but, instead of injecting PMMA under high pressure directly after positioning the needle, a balloon is first inflated in the compressed vertebra and the cement then injected into the thus-formed cavity under low pressure [12].

Owing to the relatively benign symptomatology in the present two cases, it was chosen to treat the patients conservatively by anticoagulation with warfarin, although two authors have reported the successful removal of a cement embolus from the central pulmonary arteries $[8,13]$. This treatment was initiated because PMMA is known to activate platelets in vitro [14] and promote thrombus formation in vivo [15]. The long-term effects of the intravascular presence of PMMA and barium sulphate on the pulmonary vasculature or the cardiopulmonary system in toto are unknown. PMMA can, in rare cases, cause allergic reactions [16]. Since bacteria can easily adhere to PMMA [17], the risk of infection of this foreign material should also be borne in mind.

With the increasing use of percutaneous vertebroplasty, we believe that serious reflection about the application of this technique is mandatory, and that further research into the treatment options and long-term effects of polymethylmethacrylate emboli in the pulmonary vasculature are necessary.

\section{REFERENCES}

1 Diamond TH, Champion B, Clark WA. Management of acute osteoporotic vertebral fractures: a nonrandomised trial comparing percutaneous vertebroplasty with conservative therapy. Am J Med 2003; 114: 326-328.

2 Cotten A, Dewatre F, Cortet B, et al. Percutaneous vertebroplasty for osteolytic metastases and myeloma: effects of the percentage of lesion filling and the leakage of methyl methacrylate at clinical follow-up. Radiology 1996; 200: 525-530.

3 Cortet B, Cotten A, Boutry N, et al. Percutaneous vertebroplasty in the treatment of osteoporotic vertebral compression fractures: an open prospective study. J Rheumatol 1999; 26: 2222-2228.

4 McGraw JK, Cardella J, Barr JD, et al. for the Society of Interventional Radiology Standards of Practice Committee, Society of Interventional Radiology quality improvement guidelines for percutaneous vertebroplasty. J Vasc Interv Radiol 2003; 14: S311-S315.

5 Bernhard J, Heini PF, Villiger PM. Asymptomatic diffuse pulmonary embolism caused by acrylic cement: an unusual complication of percutaneous vertebroplasty. Ann Rheum Dis 2003; 62: 85-86.

6 Padovani B, Kasriel O, Brunner P, Peretti-Viton P. Pulmonary embolism caused by acrylic cement: a rare complication of percutaneous vertebroplasty. Am J Neuroradiol 1999; 20: 375-377.

7 Jang JS, Lee SH, Jung SK. Pulmonary embolism of polymethylmethacrylate after percutaneous vertebroplasty: a report of three cases. Spine 2002; 27: E416-E418.

8 Tozzi P, Abdelmoumene Y, Corno AF, Gersbach PA, Hoogewoud HM, von Segesser LK. Management of pulmonary embolism during acrylic vertebroplasty. Ann Thorac Surg 2002; 74: 1706-1708.

9 Scroop R, Eskridge J, Britz GW. Paradoxical cerebral arterial embolization of cement during intraoperative vertebroplasty: case report. Am J Neuroradiol 2002; 23: 868-870.

10 Moreland DB, Landi MK, Grand W. Vertebroplasty: techniques to avoid complications. Spine J 2001; 1: 66-71.

11 Kallmes DF, Jensen ME. Percutaneous vertebroplasty. Radiology 2003; 229: 27-36.

12 Phillips FM. Minimally invasive treatments of osteoporotic vertebral compression fractures. Spine 2003; 28: S45-S53.

13 Francois K, Taeymans Y, Poffyn B, Van Nooten G. Successful management of a large pulmonary cement embolus after percutaneous vertebroplasty: a case report. Spine 2003; 28: E424-E425.

14 Ware JA, Kang J, DeCenzo MT, et al. Platelet activation by a synthetic hydrophobic polymer, polymethylmethacrylate. Blood 1991; 78: 1713-1721.

15 Tepe G, Duda SH, Hanke H, et al. Covered stents for prevention of restenosis. Experimental and clinical results with different stent designs. Invest Radiol 1996; 31: 223-229.

16 Kaplan K, Della Valle CJ, Haines K, Zuckerman JD. Preoperative identification of a bone-cement allergy in a patient undergoing total knee arthroplasty. J Arthroplasty 2002; 17: 788-791.

17 Chang CC, Merritt K. Microbial adherence on poly(methyl methacrylate) (PMMA) surfaces. J Biomed Mater Res 1992; 26: 197-207. 